\title{
Decreasing Cognitive Load for Learners: Strategy of Web-Based Foreign Language Learning
}

\author{
Jianfeng Zhang ${ }^{1}$ \\ ${ }^{1}$ College of Humanities and Foreign Languages, Xi' an University of Science and Technology, China \\ Correspondence: Jianfeng Zhang, College of Humanities and Foreign Languages, Xi'an University of Science \\ and Technology, Lintong District, Xi'an 710600, Shanxi, China. Tel: 86-135-7225-3626. E-mail: \\ zhangjianfeng091024@126.com
}

Received: February 19, $2013 \quad$ Accepted: March 4, $2013 \quad$ Online Published: March 7, 2013
doi:10.5539/ies.v6n4p134
URL: http://dx.doi.org/10.5539/ies.v6n4p134

The research is financed by Scientific Research Program Funded by Shaanxi Provincial Education Department (Program No. 12JK0297).

\begin{abstract}
Cognitive load is one of the important factors that influence the effectiveness and efficiency of web-based foreign language learning. Cognitive load theory assumes that human's cognitive capacity in working memory is limited and if it overloads, learning will be hampered, so that high level of cognitive load can affect the performance of learning and will create a series of negative impacts; therefore, to improve the efficiency of foreign language learning, the structure of cognitive load in the web-based environment should be analyzed because it is the foundation of reasonable and efficient use of web-based learning. Based on the features of web-based learning, in order to decrease the total load, learners' extraneous and intrinsic cognitive load should be greatly decreased and germane cognitive load can be properly increased. In this way, learners' motivation and initiative can be inspired and the learning quality will be improved significantly.
\end{abstract}

Keywords: cognitive load theory, network environment, foreign language learning

\section{Introduction}

With the rapid development of information network and technology and its wide application in education, based on computers and Internet, autonomous inquiry foreign language learning model, which relies mainly on learners and emphasizes that learners should inquire knowledge actively is paid more and more attention. Whereas in the network environment, because of huge amount and nonlinear structure of the information, foreign language learners are easily distracted and even get lost in the information so much so that their cognitive load is overloaded and results in poor academic performance. Therefore, it is necessary and significant to analyze the cognitive load of web-based foreign language learning and to stimulate learners' motivation and initiative in order to improve the effectiveness and efficiency of learning.

\section{Literature Review}

\subsection{Cognitive Load Theory}

Cognitive load theory (Sweller 1988, 2010; Sweller et al. 1998) is concerned with the learning of complex cognitive tasks, in which learners may be overwhelmed by the number of interactive information elements that need to be processed simultaneously before meaningful learning can commence. Cognitive load theory assumes human's cognitive capacity in working memory is limited and only stores about seven elements but can operate on just two to four elements. Whereas long-term memory that contains chunks of information called by schemas is unlimited. Schemata are assumed to be abstracted in working memory and may eventually become automatized due to practice. Human's knowledge comes from these schemata but working memory cannot process many elements simultaneously. So the basic idea of cognitive load theory is that processing instructional information results in cognitive load, which is located in working memory and affects learning outcomes (Peter et al. 2009). In learning process, to improve the academic performance and learning quality, the limited working memory should be fully used and the unrelated cognitive load should be decreased as much as possible. 
Cognitive load theory distinguishes three different types of contributions to total cognitive load (Ton, 2010): intrinsic cognitive load (ICL), extraneous cognitive load (ECL) and germane cognitive load (GCL). ICL mainly sources from the degree of complexity of the learning task, learners' level of knowledge and interactions between those two factors; ECL is also called invalid load that is caused by improper instructional design and material used to present the content; and finally, ECL refers to learners' effective cognition to the learning tasks and their cognitive resources that they can invest in the learning process, so this load type is helpful and useful for effective learning. In effect, the three types of cognitive load are assumed to be additive and the sum is called total cognitive load. If the cognitive load requires more working memory recourses than the learners have, it will cause cognitive overload and the learning activities are unable to carry out ineffectively and smoothly.

ICL is imposed by the basic characteristics of the learning material, which contains a large number of interactive elements (Bannert 2002). Generally speaking, learning material cannot be altered randomly but learning tasks are able to be split and interpreted deliberately. At the same time, interactive elements can be reduced by enriching the prior knowledge learners bring to the learning task so that ICL is decreased and the limited working memory will deal with the information efficiently.

ECL hurts learning because learners' working memory resources must be used for activities which are irrelative to schemata acquisition (Roxana, 2004). In order to decrease ECL, instructional design can be improved and the rendering process or ways of learning material should be optimized.

Conversely, different from the ICL and ECL that hamper the learning, GCL promotes learning by having learners devote more cognitive resources through increased effort and motivation (Moreno et al. 2001). So GCL should be properly increased by optimizing learners' cognitive structure.

\subsection{Cognitive Load in E-Learning}

With the popularization of Internet, the demand of e-learning has greatly increased (Chang et al. 2009). The e-learning instruction is quite different from the traditional classroom context. Generally speaking, the design of e-learning and the actual use happen in two different time and environment. Moreover, because of the absence of the instructor and peer, learners must reintegrate the teaching and learning process (Keegan, 1996), which may increase the cognitive load so that learners have to stop learning in frustration.

In addition, a lot of e-learning materials are built around very complex learning tasks, which include a large number of interacting elements. Learners must be coordinated in working memory in order to reach coherent performance. Some element interactivities are so high that cognition overloads and learners easily get lost in those learning materials, or worse, develop a misconception and hamper the efficient learning.

Cognitive load is one of important factors to influence e-learning outcomes. Therefore, in the web-based foreign language learning, the cognitive load of learners must be considered carefully. To obtain a successful learning process, learners' extraneous and intrinsic cognitive load should be greatly decreased and germane cognitive load can be properly increased.

\section{The Structure of Cognitive Load of Web-Based Foreign Language Learning}

Compared with the traditional foreign language learning, the model of web-based learning has possessed more advantages but because of its own characteristics, cognitive overload easily occurs in the web-based environment. According to a cognitive theory of web-based learning (Mayer and Moreno 2003), a successful learning process includes learners': (a) meaningful interaction with academic materials (Moreno, Mayer, Spires and Lester 2001); (b) selection of relevant verbal and non-verbal information (Paivio 1986); (c) organization of information into corresponding mental models or representations (Mayer and Moreno 2002; Moreno and Mayer 2002); and (d) integration of new representations with existing knowledge (Pressley, Wood, Woloshyn, Martin, King and Menke 1992). So to improve the efficiency of foreign language learning, the structure of cognitive load in the web-based environment should be analyzed because it is the foundation of reasonable and efficient use of web-based learning.

\subsection{The Structure of Intrinsic Cognitive Load}

Firstly, in the environment of web-based foreign language learning, learners are expected to learn how to use network technology and software including some skills such as operating computers, browsing web pages, sending and receiving emails, discussing online and posting assignments etc. If foreign language learners have low levels of technology knowledge and skills which mean that working memory can't automatically get corresponding schemata from long-term memory, they will not acquire knowledge in the web-based learning environment. The learners' level of technology skills are vital variables when considering the design of 
web-based foreign language learning. If technology skills and language knowledge are learned concurrently, intrinsic cognitive load that hampers learning will increase.

Next, information resources in the web-based environment are extremely rich. Although foreign language learners are easily able to gain authentic and comprehensive learning material as well as practicing in the real context, yet these applications usually contain complex learning tasks that include a great number of interacting elements. According to the cognitive load theory, it must increase the load of working memory in order to rethink and reach understanding. So the complexity and element interactivity in the web-based environment also increase the intrinsic genitive load of foreign language learners.

\subsection{The Structure of Extraneous Cognitive Load}

Although the nonlinear structure of network information resources provides flexible context for foreign language learners, sometimes learners are easily lost in the Internet because of frequently jumping web pages, numerous links and improper presentation of information, which may increase the learners' burden to acquire language knowledge, result in network trek, fatigue and even frustration. So it is hard for learners to establish a complete knowledge system and the extraneous cognitive load will increase to impact the process of foreign language learning.

On the other hand, in the web-based environment, the huge information resources usually include some redundant information that is excessive, repeated and unnecessary. When confronting and dealing with this extra and useless information, learners' cognitive resources will be occupied and they have to consume more working memory to handle and dispose this content. At the same time, if the combination of information is too great, learners will not develop an understanding of the leaning content as intended and the phenomena of impatience and anxiety may appear so that the extraneous cognitive load increases greatly.

In addition, the openness of academic material in web-based environment can consume the limited attention rescores of foreign language learners. When learning material is demonstrated by multimedia, some texts are combined with video and audio; some mother language and target language are presented at the same time. Definitely, these approaches are able to attract the interest of foreign language learners, but the information that is unrelated with learning tasks is inevitable to cost and distract learners' attention. Sometimes learning tasks are forgotten and the extraneous cognitive load will be increased as well. Therefore, the performance of foreign language learning is inefficient.

\subsection{The Structure of Germane Cognitive Load}

Germane cognitive load is associated with processes which are directly relevant learning, such as foreign language learners' motivation, autonomous learning, collaborative learning, self-monitor and management. In the web-based environment, Internet can provide unique contextual models and abundant instructional resources which can be fully utilized to improve their interest in foreign language learning and stimulate their motivation. In the meantime, based on the web, autonomous learning and collaborative learning can help learners to monitor and manage their learning process to accomplish the learning missions and achieve the purposes to acquire language knowledge. Finally, this kind of knowledge will successfully transfer the communicative ability which can automatically output. Unfortunately, because of the factors of individual differences, learning environment, time, efforts, the germane cognitive load is usually insufficient. So based on the decrease of intrinsic and extraneous cognitive load, germane cognitive should be increased properly to improve the performance of foreign language learning.

\section{The Control Strategy of Cognitive Load Level of Web-Based Foreign Language Learning}

Managing cognitive load level is a critical issue to designing web-based foreign language learning. The advantages of web-based learning should be completely used to decrease the intrinsic and extraneous cognitive load as well as increasing the germane cognitive load to achieve the goal of controlling foreign language learners' cognitive load. The strategy is shown in table 1. 
Table 1. Strategy of control cognitive load

\begin{tabular}{lll}
\hline \multicolumn{1}{c}{ Cognitive load } & \multicolumn{1}{c}{ Strategy } \\
\hline Decreasing intrinsic cognitive load & - & \multicolumn{1}{c}{ Training network technology \& skills } \\
& - & Establishing foreign language learning guides \\
Decreasing extraneous cognitive load & - Reducing web pages jumping \\
& - Deleting redundant information \\
Increasing germane cognitive load & - Demonstrating academic material \\
& - Stimulating learning motivation \\
& - Providing feedback \\
&
\end{tabular}

\subsection{Decreasing Intrinsic Cognitive Load}

At first, learners' network technology and skills should be trained. Reducing the processing capacity of information that is unnecessary is the most direct approach to decrease the cognitive load. Learners are expected to use technology and software as a part of a content learning strategy; therefore, at the beginning of the web-based foreign language learning, it is essential that learners should get enough training and should be very familiar with the basic computer and Internet operation skills to ensure that working memory can abstract this kind of information from long-term memory automatically so that intrinsic cognitive load will be decreased and learners will have enough cognition to input into foreign language learning.

And establishing foreign language learning guides is necessary. In web-based environment, learning guides which are designed clearly, definitely and logically can deconstruct the complex learning tasks and provide the train of thought for foreign language learners. After learners have grasped and understood the basic language concepts and have formed schemata, learning guides will propose the next task which is more complicated so that foreign language learners can follow in proper sequence. Moreover, learning guides are able to promote the interactivity between foreign language learners and academic material. During the web-based learning process, some complex interacting elements may occur when accomplishing a new mission, but learning guides can help to monitor the whole process and to give some advice when some complicated tasks appear. Therefore, well-designed foreign language learning guides aids in decreasing intrinsic cognitive load which is caused by dealing with interacting elements.

In many cases, in is assumed that using technology will enhance learning efficacy (Clark \& Paivio, 1991). Computer-mediated aids refer to web texts which accompany with build-in aids, such as online dictionaries, online encyclopaedias, computer pronunciation etc. In the web-based foreign language learning, using computer-mediated aids can reduce learners' cognitive load, release more cognitive resources for language learning activities and effectively promote the results of incidental vocabulary learning. So proper use of computer-mediated aids can decrease intrinsic cognitive load as well.

\subsection{Decreasing Extraneous Cognitive Load}

Reducing web pages jumps helps to decrease extraneous cognitive of foreign language learners. The more links learning interface include, the more cognitive efforts learners will have to pay; the more the relationship of web browser is complicated, the more the learners need to spend time understanding or memorizing those learning paths and the cognitive load becomes higher and higher. Therefore, in web-based environment, web pages jumping should be reduced as much as possible and some clear structural diagrams should be set up to help foreign language learners save cognitive resources and decrease their extraneous cognitive load.

Redundant information should be deleted. In the process of foreign language learning, the learning content can be interpreted clearly by only one way of presentation, but instructors use two or more ways to demonstrate the same content, so redundant information will appear. When learners deal with one way of input and they are forced to handle other unnecessary information, their extraneous cognitive load is bound to be increased. For example, in listening instruction, some instructors are accustomed to using short English movies which include bilingual subtitles. The purpose of this practice is to promote learners' listening comprehension, so when foreign language learners use these kinds of movies to help them improve their listening skills, they have to deal with the acoustic information and compel to handle texts of two languages at the same time. The texts increase learners' 
extraneous cognitive load and will impact the effect of listening comprehension. Therefore, according to actual needs, instructors should delete all subtitles or reserve subtitle of one language to decrease learners' cognitive load.

Academic material should be demonstrated reasonably and logically. The disorder ways of presentation increase cognitive load, so well-designed academic material presentation plays vital role in web-based foreign language learning. Generally speaking, the ways should be diverse. For example, the texts of foreign language could be mixed with some video material, but the video material must be carefully and tightly integrated; otherwise redundant information may appear simultaneously. If the relationship between different ways of presentation can be well organized and coordinated, foreign language learners' extraneous load will be decreased and learning will be promoted.

\subsection{Increasing Germane Cognitive Load}

Under some circumstance, it may be necessary to increase learners' motivation and encourage them to employ learning process which yield germane cognitive load. Awaken learners' cognitive inputs allows them to consciously pay more cognitive efforts and to enhance cognitive power that puts limited attention resources on foreign language learning. Therefore, the first step of stimulation of learning motivation is to attract foreign language learners' attention. If they are interested in learning content, their curiosity will be aroused. And then, learning goals and content should be established the connection depending on the specific information and situation. When learners have learned about the learning goals and content, instructors should help them to build confidence and to believe that they are able to master the learning content and to achieve learning goals successfully. So in the web-based environment, foreign language instructors must fully consider learners' abilities and conditions to design and stimulate their learning motivation to increase learners' germane cognitive load improperly.

Timely feedback increases germane cognitive load. In the web-based foreign language learning, the feedback of learning outputs is favorable toward learning about the next learning content and goals. On the other hand, foreign language learners need to satisfy with their achievements. Feedback plays an important role in the whole learning process to help learners form a virtuous circle so that foreign language learning can be continued. Therefore, it is necessary to establish performance-based award system which is useful to reserve learners' motivation and to increase their germane cognitive load.

Autonomous and collaborative learning also helps increase germane cognitive load. In the module of autonomous learning, learners are allowed to fully use information from Internet, online resources, free courseware and simulation software that can imitate authentic language environment for them to inquire. However, some problems may occur and can't be effectively solved by autonomous learning so the collaborative learning is also very necessary. In the module of collaborative learning, learners share information and recourses to settle these problems. Nowadays, the reach of the Internet makes it possible to unite geographically-scattered learners in a virtual classroom. Methods such as BBS, ICQ, and MSN etc. will allow learners both to proceed at their own pace, and to intact with one another and their instructors so that all problems can be solved and the results of inquiring tasks are formed. As a whole, during those two learning methods, learners dominate the cognitive process by active inquiry, thinking and construction of foreign language knowledge and professional skills so that when they improve their language proficiency quickly, they gain knowledge of specific fields as well (Zhang, 2013). Therefore, arranging appropriate ways of learning can increase germane cognitive load properly.

\section{Conclusion}

Cognitive load is one of the important factors that influence the effectiveness and efficiency of web-based foreign language learning. To some extent, the features of network may increase learners' cognitive load and hamper the language learning. However, if the web-based environment can be utilized rationally and properly, it is a useful way to decrease cognitive load meanwhile. In addition, it is only a theoretical research in decreasing cognitive load for web-based foreign language learners so empirical evaluation of the theoretical strategy should follow this study.

\section{References}

Bannert, M. (2002). Managing cognitive load-recent trends in cognitive load theory. Learning and Instruction, 12, 139-146. http://dx.doi.org/10.1016/S0959-4752(01)00021-4

Chang, Y. C., Kao, W. Y., Chu, C. P., \& Chiu. C. H. (2009). A learning style classification mechanism for e-learning. Computer \& Education, 53, 273-285. http://dx.doi.org/10.1016/j.compedu.2009.02.008 
Clark, F. M., \& Paivio, A. (1991). Dual coding theory and education. Educational Psychology Review, 3, 149-210. http://dx.doi.org/10.1007/BF01320076

Keegan, D. (1996). Foundations of Distance Education (3rd ed). London: Routledge.

Mayer, R. E., \& Moreno, R. (2003). Nine ways to reduce cognitive load in multimedia learning, Educational Psychologist, 38, 43-52. http://dx.doi.org/10.1207/S15326985EP3801_6

Moreno, R., Mayer, R. E., Spires, H. A., \& Lester, J. C. (2001). The case for social agency in computer-based teaching: Do students learn more deeply when they interact with animated pedagogical agents? Cognition and Instruction, 19, 177-214. http://dx.doi.org/10.1207/S1532690XCI1902_02

Paivio, A. (1986). Mental Representations: A Dual Coding Approach. Oxford, England: Oxford University Press.

Peter, G., Katharina, S., \& Gabriele C. (2009). The scientific value of cognitive load theory: A research agenda based on the structuralist view of theories. Educational Psychology Review, 21, 43-54. http://dx.doi.org/10.1007/s10648-008-9096-1

Pressley, M., Wood, E., Woloshyn, V., Martin, V., King, A., \& Menke, D. (1992). Encouraging mindful use of prior knowledge: Attempting to construct explanatory answers facilitates learning. Educational Psychologist, 27, 91-109. http://dx.doi.org/10.1207/s15326985ep2701_7

Roxana, M. (2004). Decreasing cognitive load for novice students: Effects of explanatory versus corrective feedback in discovery-based multimedia. Instructional Science, 32, 99-113.

Sweller, J. (1988). Cognitive load during problem solving: Effects on learning. Cognitive Science, 12, 257-285. http://dx.doi.org/10.1016/0364-0213(88)90023-7

Sweller, J. (2010). Element interactivity and intrinsic, extraneous and germane cognitive load. Educational Psychology Review, 22, 123-138. http://dx.doi.org/10.1007/s10648-010-9128-5

Sweller, J., Van Merriënboer, J. J. G., \& Paas, F. (1998). Cognitive architecture and instructional design. $\begin{array}{llll}\text { Educational Psychology 251-295. } & \text { Review, }\end{array}$ http://dx.doi.org/10.1023/B:TRUC.0000021808.72598.4d

Ton, J. (2010). Cognitive load theory, educational research, and instructional design: some food for thought. Instructional Science, 38, 105-134. http://dx.doi.org/10.1007/s11251-009-9110-0

Zhang, Jianfeng. (2013). The ESP Instruction: A Study Based on the Pattern of Autonomous Inquiry. English Language Teaching, 3, 72-77. http://dx.doi.org/10.5539/elt.v6n3p72 